\title{
BIOMETRY AND AUTO-FLUORESCENCE OF THE ANTERIOR OCULAR SEGMENT IN DIABETICS WITH AND WITHOUT AUTONOMIC NEUROPATHY: A Case Control Study
}

\author{
JOHN M. SPARROW ${ }^{1}$, H. A. W. NEIL ${ }^{2}$ and ANTHONY J. BRON ${ }^{1}$ \\ Oxford
}

\begin{abstract}
SUMMARY
The biometry and auto-fluorescence of the anterior ocular segment were examined in a case control study of two populations of diabetics. Cases, with diabetic autonomic neuropathy, and controls without neuropathy (forty in each group) were selected from a community based diabetic population and matched individually for age, sex, and type of diabetes. Scheimpflug and autofluorescence anterior segment photography were performed and analysed by digital image analysis in a masked fashion. There were differences between the groups in axial lens thickness, front radius of curvature of the lens, anterior chamber depth and lenticular autofluorescence. These findings are discussed in the context of the known association between autonomic neuropathy and narrow angle glaucoma, and possible common mechanisms of tissue damage in diabetes.
\end{abstract}

Systemic autonomic dysfunction has been associated with primary glaucomas and ocular hypertension, ${ }^{1.2 .3}$ with a higher prevalence of autonomic dysfunction having been found in subjects with narrow angles (closed angle glaucoma or ocular hypertension in a narrow angle situation), than wide angles. ${ }^{1.24 .5}$ Autonomic denervation hypersensitivity of parasympathetically innervated iris musculature has been demonstrated in ocular hypertension $^{6}$ and primary open angle glaucoma. ${ }^{7}$ Both parasympathetic and sympathetic denervation hypersensitivity of iris musculature have each been demonstrated in excess in untreated subjects with primary closed angle and primary open angle glaucoma. ${ }^{5}$ In a diabetic population, shallower anterior chambers have been found associated with reduced pupil diameter (sympathic malfunction). ${ }^{8}$

'Nuffield Laboratory of Ophthalmology, University of Oxford.

${ }^{2}$ Department of Public Health \& Primary Care. University of Oxford. Correspondence to: Dr John M. Sparrow. DPhil. FRCS, FCOphth. Clinical Lecturer, Department of Ophthalmology, University of Leicester, The Leicester Royal Infirmary, Leicester LEl 5WW.
Diabetic subjects are known to have increased axial lens thickness ${ }^{9}$ and this increase is dependent on diabetic duration in early onset diabetics. ${ }^{10.11}$ Abnormally shallow anterior chambers are characteristic of eyes with primary closed angle glaucoma, although certain other factors appear to operate (possibly including autonomic neuropathy) in the precipitation of an acute angle closure attack. ${ }^{5.12}$ Diabetes is the commonest underlying cause of autonomic neuropathy, reported to be present in $15 \%$ to $40 \%$ of diabetics. ${ }^{13.14 .15}$

Lenticular blue/green auto-fluorescence is increased in diabetes ${ }^{10.16 .17 .18 .19 .20}$ this increase being duration dependent, ${ }^{19}$ particularly in early onset diabetics, ${ }^{20}$ and is also dependent on glycaemic control. ${ }^{21}$ The blue/green fluorescence appears to be due to a single fluorophor. ${ }^{22}$ Nonenzymatic glycosylation of lens proteins may be the underlying chemical mechanism behind increased lenticular UV/blue auto-fluorescence, ${ }^{23}$ and has been suggested as a candidate for diabetic tissue damage. ${ }^{24}$ The polyol pathway may be involved in diabetic neuropathic damage, ${ }^{25.26}$ although in the crystalline lens of human adult diabetics the activity of aldose reductase is limited ${ }^{27.28}$ and the evidence for sorbitol induced lens damage in "senile" diabetic cataract has been questioned. ${ }^{29}$ Low concentrations of polyol degradation products could however play a glycating role, with fructose having been shown to be 10 times more reactive in the production of protein bound $\mathrm{UV} / \mathrm{blue}$ fluorescent glycation products than glucose. ${ }^{30}$ There is evidence which suggests that the blue/green fluorogen in the lens may be derived from the UV/blue fluorogen. ${ }^{31.32}$

The present study was designed to test two hypotheses. Firstly, in view of the high prevalence of systemic autonomic neuropathy found in patients with angle closure glaucoma, subjects with autonomic neuropathy may have demonstrable disturbances of anterior segment biometry. Such a disturbance may predispose these individuals to acute angle closure events. Secondly, factors leading to 
increased lenticular auto-fluorescence in diabetics may be similar to factors resulting in neuropathic tissue damage. If so a common underlying biochemical mechanism may exist.

\section{SUBJECTS AND METHODS}

A case control study design was used to compare subjects with and without autonomic neuropathy. All participants had diabetes, and cases and controls were individually matched for age, sex and type of diabetes (early or late onset). Participants were selected from a community based population of diabetics previously identified and studied in the Oxford area. ${ }^{33}$ The autonomic status of these patients was known before they were invited to participate in the study, which allowed case control matching (HAWN) to be performed before recruitment. Patients who were using drugs with known autonomic effects were excluded from the study.

Autonomic function was assessed by measurement of both darkness pupil diameter and heart rate variability. For the pupillometric test, the right eye was photographed with a Polaroid CU-5 close up camera with a $75 \mathrm{~mm}$ lens and built in electronic flash ring ${ }^{34}$ after the patient had been in darkness for 30 seconds. The horizontal diameter of the dark adapted pupil was expressed as a percentage of the horizontal corneal diameter. Heart rate variability was measured by a computerised technique at rest and in response to both a single deep breath and a valsalva manoeuvre. ${ }^{14}$ Results of the pupillometric and cardiovascular tests below the 2.5 centile for the age related normal ranges were defined as abnormal. ${ }^{34.355 .36 .37}$

Ocular assessments were made in random order at the Oxford Eye Hospital by a single masked examiner/photogapher (JMS) using a Scheimpflug camera ${ }^{38.39 .40}$ and a modified Zeiss anterior segment camera for auto-fluorescence. ${ }^{20}$ Photography was performed under mydriasis (G. Tropocamide $1 \%$ and G. Phenylephrine 10\%). Ilford XP1 film was used throughout, and was developed according to a standard protocol. The repeatability of the methods of digital image analysis of Scheimpflug and auto-fluorescence photographs has been published. ${ }^{41}$ Informed verbal consent was obtained from all subjects prior to their recruitment, the study protocol having been approved by the Central Oxford Research Ethics Committee (ref no 1211).

Eyes were excluded from the analysis if aphakic, or if individual parameters were not available from the photographic images. In general the analysis was performed on both eyes using the intraclass correlation model of Rosner, which takes account of the inter-eye correlation and avoids overestimation of significance levels. ${ }^{42.43}$ The analysis was performed using the Generalised Linear Interactive Modelling (GLIM) System of the Numerical Algorithms Group* on a mainframe computer (VAX).

\section{RESULTS}

Of the individually matched subjects in each group, 14 were female and eight had early onset diabetes. The mean ages $( \pm S D)$ of the cases and controls were 59.7 years $( \pm 13.6)$ and 60.3 years $( \pm 14.0)$, and the mean diabetic durations were 16.3 years $( \pm 10.6)$ and 15.0 years $( \pm 8.0)$ respectively. An analysis of the effect of ageing on biometric parameters is presented in Table I, where the main finding is that there are differences in the ageing effects for the case/control sub-groups. In the control group it will be seen that there are statistically significant ageing effects for all parameters studied. Among the cases with neuropathy however, three of the parameters studied show no significant ageing effects, with a significant but much weaker ageing effect found for axial lens thickness in this group. In each instance, the age slope for the neuropathy group is less steep than that of the non-neuropathy group. The correlation coefficients for age ( $\mathrm{R}$ squared) are all higher for controls than for cases. In addition to the individual case/control matching described above, prior statistical adjustment was made in these analyses for the potentially confounding effects of sex, diabetic duration, type of diabetes and diabetic treatment.

An analysis of the interaction effect between age and case/control status is presented in Table II. This analysis confirms that for front radius of curvature and auto-fluorescence the age slopes of the regression lines are significantly "flatter" for cases than controls. No statistically significant case/control differences were found for the age slopes of anterior chamber depth and lens thickness. These analyses are adjusted for the potentially confounding effects noted above.

The analysis of the overall effects of autonomic neuropathy and its various sub-types is summarised in Table III. This is a main effects analysis, in which a comparison is made between (sub-) groups with various autonomic function test abnormalities and the control group. The analyses have been adjusted for age (treated as a covariate) as well as the other potentially confounding effects noted above. Increased lens thickness was found in subjects with abnormal expiratory/inspiratory ratios (EI) and "multiple" (two or more, MULT) autonomic abnormalities, with reduced front radii of curvature (steeper front curves) being found in all sub-groups with autonomic abnormalities, although this effect did not quite reach the $95 \%$ probability level in the comparison between all cases and controls (NEUROP).

\section{DISCUSSION}

The normal growth throughout life of the crystalline lens results in an increase in lenticular thickness and a steepening of the front and back curvatures of the lens with age. Accompanying these changes is a reduction in the anterior chamber depth of the eye. Diabetics have disturbances of their anterior segment biometry, with on average, larger lenses, steeper anterior lens curvatures and shallower anterior chambers. ${ }^{9.10 .11}$

\footnotetext{
*Numerical Algorithms Group Ltd. (NAG), Wilkinson House, Jordan Hill Road, Oxford OX2 8DR, UK.
} 
Table I. Summary of the ageing effects on the biometric and autofluorescence parameters in cases (with neuropathy) and controls (without neuropathy) after taking account of the potentially confounding effects of sex, diabetic duration, type of diabetes and diabetic treatment

\begin{tabular}{|c|c|c|c|c|}
\hline & $\begin{array}{l}\text { Age } \\
\text { slope } \\
\text { (units/ } \\
\text { year) }\end{array}$ & $95 \% \mathrm{CI}$ & $\mathrm{P}$ & $\begin{array}{l}\text { R square } \\
\text { (correlation } \\
\text { for } \\
\text { regression } \\
\text { on age) }\end{array}$ \\
\hline \multicolumn{5}{|c|}{ CASES (with neuropathy) } \\
\hline $\mathrm{AC}(\mathrm{mm})$ & -0.014 & \pm 0.015 & NS & 0.11 \\
\hline $\mathrm{LN}(\mathrm{mm})$ & 0.016 & \pm 0.014 & 0.019 & 0.16 \\
\hline $\mathrm{FR}(\mathrm{mm})$ & -0.015 & \pm 0.029 & NS & 0.0004 \\
\hline FL (arb) & -0.208 & \pm 0.361 & NS & 0.07 \\
\hline \multicolumn{5}{|c|}{ CONTROLS (without neuropathy) } \\
\hline $\mathrm{AC}(\mathrm{mm})$ & -0.019 & \pm 0.016 & 0.020 & 0.30 \\
\hline $\mathrm{LN}(\mathrm{mm})$ & 0.030 & \pm 0.013 & 0.000003 & 0.49 \\
\hline $\mathrm{FR}(\mathrm{mm})$ & -0.069 & \pm 0.053 & 0.010 & 0.32 \\
\hline FL (arb) & 0.699 & \pm 0.382 & 0.00035 & 0.58 \\
\hline
\end{tabular}

Key: $95 \% \mathrm{CI}=95 \%$ Confidence Interval; $\mathrm{P}=$ probability for age slope calculated by the intraclass correlation model of Rosner (see text); $\mathrm{AC}=$ Anterior Chamber depth; LN = Axial Lens Thickness; FR = Front Radius of curvature of the lens; $\mathrm{FL}=$ Blue-Green Auto-Fluorescence of the lens (arb = arbitrary fluorescence units).

A shallow anterior chamber is generally considered a prerequisite for angle closure glaucoma. Shallower anterior chambers have been found in diabetics ${ }^{10.11}$ and in subjects with impaired glucose tolerance. ${ }^{44}$ In a diabetic population, reduced pupil diameter (sympathetic malfunction) has been found in association with shallower anterior chambers. ${ }^{8}$ Autonomic neuropathy may contribute to the events leading to acute angle closure glaucoma. ${ }^{1,2,5}$ The present study has shown certain features of anterior segment biometry to be preferentially disturbed in diabetics with established autonomic neuropathy. The lens changes in patients with neuropathy are consistent with those expected in diabetes, ${ }^{10.11}$ but they are exaggerated. Thus in Table III (right column) it will be seen that the lenses of the cases with neuropathy are larger, with shorter anterior radii of curvature, and that these are associated with shallower anterior chambers. In the table not all these changes reach the $5 \%$ significance level, but the biometric

Table II. Summary of the analysis of interaction effects showing differences between the age slopes of cases (with neuropathy) and controls (without neuropathy) after taking account of the potentially confounding effects of sex, diabetic duration, type of diabetes, and diabetic treatment

\begin{tabular}{lccc}
\hline & $\begin{array}{c}\text { Age slope } \\
\text { difference } \\
\text { (units/year) }\end{array}$ & $95 \% \mathrm{CI}$ & $\mathrm{P}$ \\
\hline $\mathrm{AC}(\mathrm{mm})$ & 0.005 & \pm 0.013 & $\mathrm{NS}$ \\
$\mathrm{LN}(\mathrm{mm})$ & 0.009 & \pm 0.011 & $\mathrm{NS}$ \\
FR $(\mathrm{mm})$ & 0.053 & \pm 0.034 & 0.0024 \\
FL (arb) & 0.536 & \pm 0.306 & 0.00062 \\
\hline
\end{tabular}

Key: Age slope difference $=$ age slope for controls minus age slope for cases $; 95 \% \mathrm{CI}=95 \%$ Confidence Interval; $\mathrm{P}=$ probability for age slope calculated by the intraclass correlation model of Rosner (see text); AC = Anterior Chamber depth; LN = Axial Lens Thickness; FR = Front Radius of curvature of the lens; $F L=$ Blue-Green Auto-Fluorescence of the lens (arb = arbitrary fluorescence units). trends are consistent in all sub-groups. The significant decrease in slope of the age by front curve regression line for the neuropathy group (Table II) is in keeping with changes found in a population of predominantly late onset diabetics as compared with non-diabetics. ${ }^{10}$ The diabetics with autonomic neuropathy however display this abnormality to a greater degree. The slope reduction with age indicates that the younger members of the population are those in whom the observed biometric disturbance is most pronounced. Reduced pupil diameter was significantly associated with steeper anterior lens curvatures, although unlike Moore et al. $^{8}$ our finding of reduced anterior chamber depth in association with smaller pupils did not reach the 5\% significance level. In interpreting these findings however it should be remembered that the measurements of the anterior chamber depth were made in eyes with dilated pupils. Although stimulation of the iris sphincter to contract is classically associated with an increased pupil block force and shallowing of the anterior chamber, ${ }^{12}$ the possibility exists that pupil dilatation could have altered the anterior chamber depth of these patients either by making it deeper or shallower, depending on the pupil block forces associated with the initial and final pupil sizes. Should this have taken place then our assessments of anterior chamber depth may have been nonrepresentative. Cycloplegia on the other hand is desirable when assessing lens biometry, as it avoids any biometric changes due to accommodation.

Increased blue/green lenticular auto-fluorescence is found in diabetics compared with controls. ${ }^{10,16,17,18,19,20}$ In a population of predominantly late onset diabetics an overall increase in fluorescence with a decrease in the slope of the age regression line in comparison to non-diabetics has been found (i.e. younger members of the diabetic population are more noticeably affected). ${ }^{10,20}$ This pattern is reflected in the present finding of an overall slight increase in lenticular fluorescence, with a significantly flatter age slope in the diabetics with neuropathy as compared to those without neuropathy. The (younger) neuropathic diabetics therefore showing an exaggeration of the expected diabetic pattern of change.

Increased auto-fluorescence among (younger) diabetics with autonomic neuropathy suggests the possibility of a common underlying mechanism of neuropathic tissue and lens damage. Lenticular fluorescence is likely to result from non-enzymatic glycation..$^{20,21,23}$ Polyol pathway intermediates (and/or degradation products), disturbances of phosphoinositide, reduced tissue myo-inositol and impaired $\mathrm{Na}^{+} \mathrm{K}^{+}$ATPase function may be of importance in the mechanism of neuropathic damage. ${ }^{25,26}$ Aldose reductance activity in adult diabetic lenses however appears to be extremely limited, ${ }^{27,28,29}$ although low level "aldose reductase" activity (possibly mediated via monosaccharide autoxidation ${ }^{29}$ ) could result in the generation of polyol degradation products sufficient to cause non-enzymatic glycation. Fructose has been shown to generate protein bound UV/blue fluorescence by a glycating mechanism at a rate ten times greater than glucose. ${ }^{30}$ The longer wavelength blue/green fluorophor may be 
Table III. Summary of the group differences (main effects analysis, and 95\% confidence intervals) for the various types of autonomic neuropathy. Tabulated are the subgroup and group differences between cases and controls for various autonomic defects, after taking account of the potentially confounding effects of age, sex, diabetic duration, type of diabetes, and diabetic treatment. Positive effects occur where the parameter measured is greater in the cases than controls and vice versa

\begin{tabular}{|c|c|c|c|c|c|c|}
\hline & $\begin{array}{c}\mathrm{PD} \\
(\mathrm{N}=22)\end{array}$ & $\begin{array}{c}\text { VAL } \\
(\mathrm{N}=17)\end{array}$ & $\begin{array}{c}\text { RR } \\
(N=8)\end{array}$ & $\begin{array}{c}E I \\
(N=17)\end{array}$ & $\begin{array}{c}\text { MULT } \\
(N=14)\end{array}$ & $\begin{array}{c}\text { NEUROP } \\
(\mathrm{N}=40)\end{array}$ \\
\hline $\mathrm{AC}(\mathrm{mm})$ & $\begin{array}{c}-0.13 \\
( \pm 0.21)\end{array}$ & $\begin{array}{c}-0.20 \\
( \pm 0.23)\end{array}$ & $\begin{array}{c}-0.23 \\
( \pm 0.30)\end{array}$ & $\begin{array}{c}-0.20 \\
( \pm 0.22)\end{array}$ & $\begin{array}{c}-0.25 \\
( \pm 0.26)\end{array}$ & $\begin{array}{c}-0.10 \\
( \pm 0.17)\end{array}$ \\
\hline $\mathrm{LN}(\mathrm{mm})$ & $\begin{array}{c}0.12 \\
( \pm 0.17)\end{array}$ & $\begin{array}{c}0.03 \\
( \pm 0.20)\end{array}$ & $\begin{array}{c}0.20 \\
( \pm 0.24)\end{array}$ & $\begin{array}{r}0.26^{*} \\
( \pm 0.17)\end{array}$ & $\begin{array}{r}0.30^{*} \\
( \pm 0.20)\end{array}$ & $\begin{array}{r}0.07 \\
( \pm 0.15)\end{array}$ \\
\hline $\mathrm{FR}(\mathrm{mm})$ & $\begin{array}{c}-0.68 * \\
( \pm 0.62)\end{array}$ & $\begin{array}{c}-0.73 * \\
( \pm 0.69)\end{array}$ & $\begin{array}{c}-0.93 * \\
( \pm 0.92)\end{array}$ & $\begin{array}{r}-0.79 * \\
( \pm 0.67)\end{array}$ & $\begin{array}{c}-0.14 * \\
( \pm 0.75)\end{array}$ & $\begin{array}{c}-0.47 \\
( \pm 0.49)\end{array}$ \\
\hline FL (arb) & $\begin{array}{c}-0.49 \\
( \pm 5.15)\end{array}$ & $\begin{array}{r}4.12 \\
( \pm 5.30)\end{array}$ & $\begin{array}{r}6.59 \\
( \pm 6.95)\end{array}$ & $\begin{array}{r}3.38 \\
( \pm 5.65)\end{array}$ & $\begin{array}{r}4.76 \\
( \pm 5.83)\end{array}$ & $\begin{array}{r}1.92 \\
( \pm 4.37)\end{array}$ \\
\hline
\end{tabular}

Key: AC = Anterior Chamber depth; LN = Axial Lens Thickness; FR = Front Radius of curvature of the lens; FL = Blue-Green Auto-Fluorescence of the lens ( $\mathrm{arb}=$ arbitrary fluorescence units); PD = Pupil diameter abnormality; VAL = Heart response to valsalva abnormal; RR = Abnormal standard deviation of R-R interval on ECG over 5 minutes; EI = Abnormal heart rate Inspiratory Expiratory ratio; MULT = Any two or more of the above autonomic function tests abnormal; NEUROP = Any autonomic neuropathy (i.e. main effects analysis of all cases and controls). 95\% Confidence intervals calculated by the intraclass correlation model; $*=\mathrm{P}<0.05$.

derived from the shorter wavelength UV/blue fluorophor. $^{31,32}$ Two mechanistic links between neuropathic tissue damage and lens damage (fluorescence) are therefore possible. Glycation by glucose (glycosylation) could occur in both the lens ${ }^{23}$ and nerves. ${ }^{24}$ Glycation by fructose, a polyol degradation product (fructation), could occur in lens and nerves ${ }^{30}$ with fructation possibly augmenting neurological tissue damage mediated by the "Sorbitol-Myo-inositol-Na ${ }^{+} \mathrm{K}^{+}$ATPase" mechanism. ${ }^{25}$

The findings of the present study suggest that the diabetics who suffer autonomic neurological damage are preferentially at risk for the development of disturbances to their anterior segment biometry. In the context of acute angle closure glaucoma, the diabetics with the biggest lenses, the shallowest anterior chambers, the most severe autonomic neuropathy (and the most fluorescent lenses) might be expected to be at greatest risk. The relative contributions of these factors remain to be determined.

The authors are grateful to Mr N. A. P. Brown, MD, FRCS, for the use of his Scheimpflug camera, and to Prof J. Mann, DM, $\mathrm{PhD}$, and Dr D. Hockaday, DPhil, FRCP, for allowing them to recruit their patients to this study. This study was supported by an Oxford Regional Health Authority Locally Organised Research Grant (No 87/14).

Key words: Anterior segment Biometry, Auto-fluorescene, Autonomic Neuropathy, Crystalline lens, Diabetes.

\section{REFERENCES}

1. Clark CV and Mapstone R: Autonomic neuropathy in closed angle glaucoma. Res Clin Forums 1985, 7: 45-50.

2. Clark CV and Mapstone R: Autonomic neuropathy in ocular hypertension. Lancet 1985, 2: 8440, 185-7.

3. Clark CV and Mapstone R: Systemic autonomic neuropathy in open angle glaucoma. Doc Ophthalmol 1986, 64: 179-85.

4. Clark CV and Mapstone R: Pupil cycle time in primary closed angle glaucoma. Can J Ophthalmol 1986, 21: 88-91.
5. Clark CV: Autonomic denervation hypersensitivity in the primary glaucomas. Eye 1989, 3: 349-54.

6. Clark CV and Mapstone R: Parasympathetic denervation hypersensiivity of the iris in ocular hypertension. Invest Ophthalmol Vis Sci 1987, 28: 1732-5.

7. Jordan K, Perry SR, McCormack PJ, Downes RN: Cholinergic supersensitivity of the iris in primary open angle glaucoma. A clinical study. Eye 1988, 2: 233-7.

8. Moore MV, Jeffcoate WJ, Haworth S: Autonomic neuropathy and the pathogenesis of glaucoma in diabetes mellitus. Diabetic Medicine 1989, 6: 717-9.

9. Brown NAP and Hungerford J: The influence of the size of the lens in ocular disease. Trans Ophthalmol Soc UK 1982, 102: 359-63.

10. Sparrow JM: The Lens in Diabetes. DPhil Thesis (1988), Linacre College, University of Oxford.

11. Sparrow JM, Bron AJ, Brown NAP, Neil HAW: Biometry of the crystalline lens in early onset diabetes. BrJ Ophthalmol 1990, 74: 654-60.

12. Mapstone R: Acute shallowing of the anterior chamber. $\mathrm{BrJ}$ Ophthalmol 1981, 65: 446-51.

13. Dyrberg T, Benn J, Christiansen JS, Hilsted J, Nerup J: Prevalence of diabetic autonomic neuropathy measured by simple bedside tests. Diabetologia 1. 1981, 20: 190-4.

14. Neil HAW, Thompson AV, John S, McCarthy ST, Mann JI: Diabetic autonomic neuropathy: the prevalence of impaired heart rate variability in a geographically defined population. Diabetic Medicine 1989, 6: 20-4.

15. O'Brien IAD, O'Hare JP, Lewin IG, Corrall RJM: The prevalence of autonomic neuropathy in insulin dependent diabetes mellitus: A case controlled study based on heart rate variability. $Q J$ Med 1986 (New series 61), 234: 957-67.

16. Helve $\mathrm{J}$ and Nieminen $\mathrm{H}$ : Autofluorescence of the human diabetic lens in vivo. Am J Ophthalmol 1976, 81: 491-4.

17. Zeimer RC and Noth JM: A new method of measuring in vivo the lens transmittance, and study of lens scatter, fluorescence and transmittance. Ophthalmic Res 1984, 16: 246-55.

18. Mosier MA, Occhipinti JR, Burstein NL: Autofluorescence of the crystalline lens in diabetes. Arch Ophthalmol 1986, 104: $1340-3$.

19. Bleeker JC, van Best JA, Vrij L, van der Velde EA, Oosterhuis A: Autofluorescence of the lens in diabetic and healthy subjects by fluorophotometry. Invest Ophthalmol Vis Sci 1986, 27: 791-4.

20. Sparrow JM, Bron AJ, Brown NAP, Neil HAW: Autofluorescence of the crystlline lens in early and late onset diabetes. Br J Ophthalmol (In Press). 
21. Larsen M, Kjer B, Bendtson I, Dalgaard P, Lund-Andersen $\mathrm{H}$ : Lens fluorescence in relation to metabolic control of insulin dependent diabetes mellitus. Arch Ophthalmol 1989, 107: 59-62.

22. Hemenger RP, Occhipinti JR, Mosier MA: Ageing parameters of the ocular lens by scanning fluorophotometry. Ophthalmic Physiol Opt 1989, 9: 191-7.

23. Pongor S, Ulrich PC, Bencsath A, Cerami A: Ageing of proteins: Isolation and identification of a fluorescent chromophore from the reaction of polypeptides with glucose. Proc Natl Acad Sci USA 1984, 81: 2684-8.

24. Cerami A, Vlassara H, Brownlee M: Glucose and aging. Scientific American 1987, 256: 90-6.

25. Greene DA, Lattimer SA, Sima AAF: Are disturbances of sorbitol, phosphoinositide and $\mathrm{Na}^{+} \mathrm{K}^{+}$ATPase regulation involved in pathogenesis of diabetic neuropathy? Diabetes 1988, 37: 688-93.

26. Bilous RW: Diabetic autonomic neuropathy. A common complication which rarely causes symptoms. $\mathrm{Br}$ Med $J$ 1990, 301(2): 565-6.

27. Crabbe MJ, Bron AJ, Peckar CO, Petchey M, Ting HH, Howard-Williams J: NADPH-oxidising activity in lens and erythrocytes in diabetic and nondiabetic patients with cataract. Br J Ophthalmol 1983, 67: 696-9.

28. Lerman S, Moran M, Matthews N: Photographic and spectroscopic correlations of human cataracts. Ophthalmic Res 1989, 21: 18-26.

29. Wolff SP and Crabbe MJ: Low apparent aldose reductase activity produced by monosaccharide autoxidation. Biochem J 1985, 226: 625-30.

30. Suarez G: Non-enzymatic browning of proteins and the sorbitol pathway. Prog Clin Biol Res 1989, 304: 141-62.

31. Lerman S: Radiant energy and the eye. Lerman S. (Ed) Vol 1, Functional Ophthalmology series. Macmillan Publishing Co. Ltd. (1980) New York, London, Toronto.

32. Yu NT, Barron BC, Kuck JRF: Distribution of two meta- bolically related fluorophors in human lens measured by laser microprobe. Exp Eye Res 1989, 39: 189-94.

33. Neil HAW, Gatling W, Mather HM, Thompson M, Thorogood M, Fowler GH, Hill DR, Mann JI: The Oxford community diabetes study: Evidence for an increase in the prevalence of known diabetes in Great Britain. Diabetic Med 1987, 4: 539-43.

34. Smith SA and Dewhurst RR: A simple diagnostic test for pupillary abnormality in diabetic autonomic neuropathy. Diabetic Med 1986, 3: 38-41.

35. Smith SE and Smith SA: Heart rate variability in healthy subjects measured with a bedside computer based technique. Clin Sci 1981, 61: 379-83.

36. Smith SA: Reduced sinus arrhythmia in diabetic autonomic neuropathy: diagnostic value of an age related range. $\mathrm{Br}$ Med J 1982, 285: 1599-601.

37. Smith SA: Diagnostic value of the valsalva ratio reduction in diabetic autonomic neuropathy: use of an age related normal range. Diabetes Med 1984, 1: 295-7.

38. Brown NAP: Slit-image photography. Trans Ophthalmol Soc UK 1969, 89: 397-408.

39. Brown NAP: An advanced slit image camera. Br J Ophthalmol 1972, 56: 624-31.

40. Brown NAP: Quantitative slit-image photography of the lens. Trans Ophthalmol Soc UK 1972, 92: 303-17.

41. Sparrow JM, Brown NAP, Shun-Shin GA, Bron AJ: The Oxford modular cataract image analysis system. Eye 1990, 4: $638-48$.

42. Rosner B: Statistical methods in ophthalmology: an adjustment for The intra-class correlation between eyes. Biometrics 1982, 38: 105-14.

43. Rosner B: Multivariate methods in ophthalmology with applications to other paired data situations. Biometrics 1984, 40: 1025-35.

44. Mapstone R and Clark CV: Prevalence of diabetes in glaucoma. Br Med J 1985, 291: 93-5. 